\title{
DEPENDENCIES OF DISCRETE-ADDITIVE FORMATION OF MICROVOLUMES OF METAL BEING SOLIDIFIED IN MULTI-LAYER MICROPLASMA POWDER SURFACING OF NICKEL ALLOYS
}

\author{
K.A. YUSHCHENKO, A.V. YAROVITSYN and N.O. CHERVYAKOV \\ E.O. Paton Electric Welding Institute, NASU \\ 11 Kazimir Malevich Str., 03680, Kiev, Ukraine. E-mail: office@paton.kiev.ua
}

\begin{abstract}
Peculiarities of heat input, bead cross-section area and efficiency were investigated at single-layer microplasma powder surfacing of nickel heat-resistant alloy JS32 on narrow substrate of 1-2 mm thickness. It is determined that series of its modes using 5-15 A welding current differs by the minimum heat input. Calculated evaluation of stress-strain state of a welded joint was carried out for its minimum and maximum level during building-up of edge of a plate using single- and three-layer surfacing. It is shown that the value of heat input in microplasma surfacing determines a width of plastic deformation zone and value of sum plastic deformations as a result of reheating in multi-layer surfacing. New technological principles were proposed for selecting the modes of multi-layer and 3D-microplasma powder surfacing of the parts from nickel heat-resistant alloys, providing the minimum heat input in a part and regulating requirements to welding current value, time of existence of metal of weld micropool in molten state and its volume. 20 Ref., 2 Tables, 10 Figures.
\end{abstract}

\begin{abstract}
Keywords: microplasma powder surfacing, narrow substrate, nickel heat-resistant alloy JS32, effective power of part heating, heat input, bead cross-section area, volume of weld micropool, surfacing efficiency, stress-strain state of welded joint
\end{abstract}

It is a well known fact that the value of heat input is a very important process parameters which characterizes weld pool dimensions, duration of its existence and area of HAZ part heated to more than $600{ }^{\circ} \mathrm{C}$ temperature in fusion welding of structural steels [1].

The value of heat input under conditions of shielded-gas, submerged-arc and coated-electrode welding using more than 50 A current can lie in $0.87-3.78 \mathrm{~kJ} / \mathrm{mm}$ range (bridge structures) [2], and is $0.6-0.9 \mathrm{~kJ} / \mathrm{mm}$ for orbital TIG welding of technological pipelines [3]. The value of heat input in welding of low-alloy steels susceptible to quenching is reasonable to regulate based on conditions of cooling of HAZ metal in $600-500{ }^{\circ} \mathrm{C}$ interval and diagrams of anisothermal austenite decay [1-3]. In microplasma welding, the value of heat input, as a rule, lies in 20 $35 \mathrm{~J} / \mathrm{mm}$ range at proportional value of current and welding speed in the range of $2-49 \mathrm{~A}$, and $5-87 \mathrm{~m} / \mathrm{h}$, respectively, for metal of $0.1-0.5 \mathrm{~mm}$ thickness [4].

Heat input value can make $0.25-3 \mathrm{~kJ} / \mathrm{mm}$ [5] applicable to repair of edges in the parts of aircraft GTE from nickel heat-resistant alloys by single-layer microplasma powder surfacing (MPPS) on narrow substrate using current up to $35 \mathrm{~A}$ [6]. A quality of basedeposited metal welded joint in multi-layer MPPS of nickel heat-resistant alloys according to crack suscep- tibility criteria depends on the value of total heat input and surfacing efficiency $[7,8]$.

Aim of the work is an investigation of relationship of heat input and size of bead section (volume of welding micropool) in single-layer MPPS on narrow substrate of 1-2 mm width and at 5-15 A current with partial feed of powder of nickel heat-resistant alloys containing strengthening $\gamma^{\prime}$-phase of more than 45 vol.\%.

Experiment procedure and experimental data processing. Surfacing was carried out under conditions of free formation over the edge of $(30-40) \times(90-$ 100) $\mathrm{mm}$ size plate from austenite stainless steel of 1 , 1.6 and $2 \mathrm{~mm}$ thickness. A distance from surface being deposited to outer cut of plasmatron made $5 \mathrm{~mm}$. A filler powder of nickel heat-resistant alloy JS32 [9] from +63 to $-160 \mu \mathrm{m}$ fraction was used. The experiments were carried out on UPNS-304M2/M3 unit. Mass of a powder portion, which is fed in a column of microplasma arc, made on average $0.14 \mathrm{~g}$. Microplasmatron PPS04 with nozzle channel diameters of 2.5 (plasma) and $4.5 \mathrm{~mm}$ (focusing) was used. Higher grade argon on GOST 10157-79 was taken as a plasma $\left(Q_{\mathrm{pl}}=11 / \mathrm{min}\right)$ and transporting $\left(Q_{\mathrm{tr}}=\right.$ $=4-5 \mathrm{l} / \mathrm{min}$ ) gas, and $\mathrm{Ar}+5 \% \mathrm{H}_{2}$ mixture was applied as a shielding gas $\left(Q_{\mathrm{sh}}=7 \mathrm{l} / \mathrm{min}\right)$.

In process of bead formation in a discrete-additive mode the welding micropool after filling by a portion 


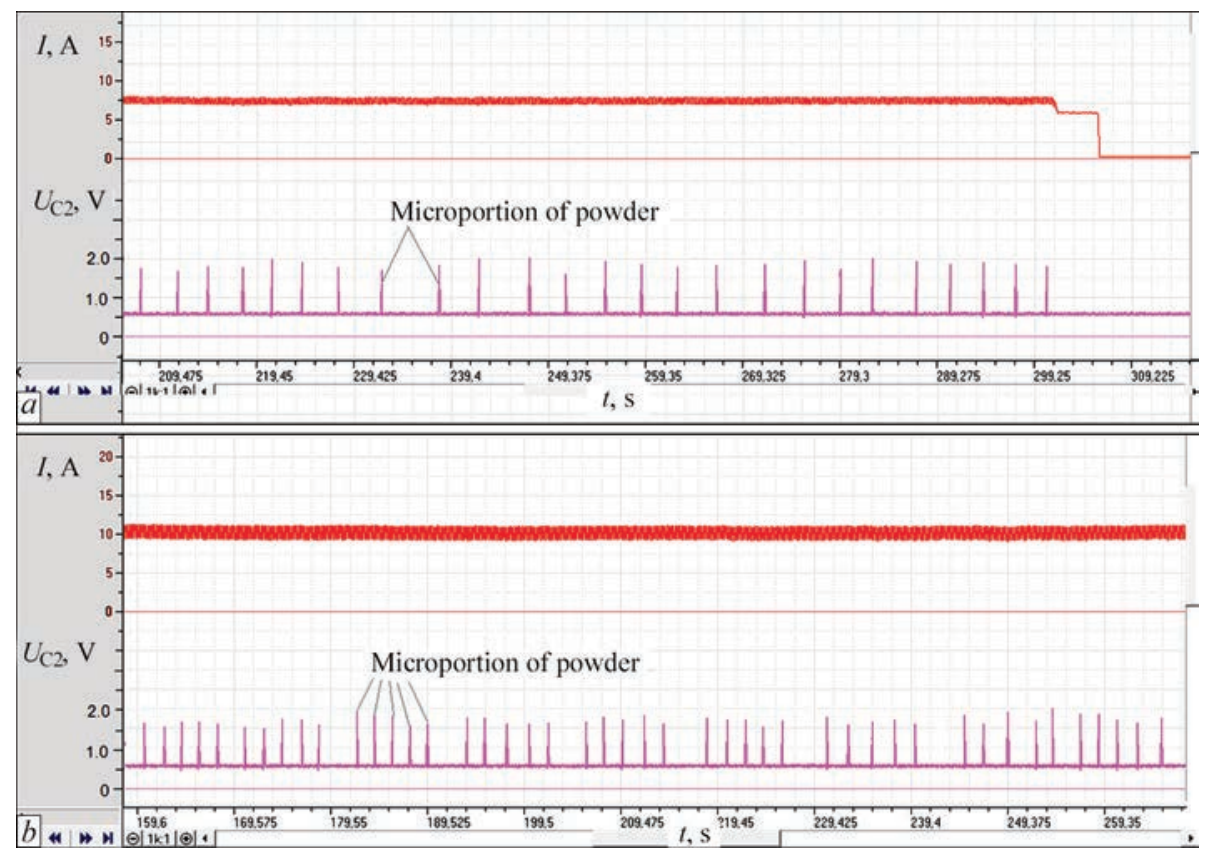

Figure 1. Fragments of oscillograms of MPPS on narrow substrate of $1.6 \mathrm{~mm}$ width with different amount of microportions of filler powder being fed in weld micropool: $a-1$ portion; $b$ - series from 5 portions; $U_{\mathrm{C} 2}$ - control signal of feeder operating mechanism corresponding to feed of 1 microportion

of liquid filler is moved forward, and its new volume is again filled. In different series of experiments it was successively increased due to input in a weld pool mirror from 1 to 5 microportions of powder (Figure 1) simultaneously with step-by-step change of welding current in 5-15 A range. A period of the disperse filler portion feeding lied in the range of $t_{\mathrm{f}}=1.5-5.0 \mathrm{~s}$ and was selected in such a way [5] as to provide a base metal wetting angle $\alpha=30-60^{\circ}$ (Figure 2, $a$ ) on a deposit leading edge proceeding from stable formation of set bead shape. If this condition was fulfilled at $t_{\mathrm{f}}=1.5-1.8 \mathrm{~s}$ in smooth increase of welding current

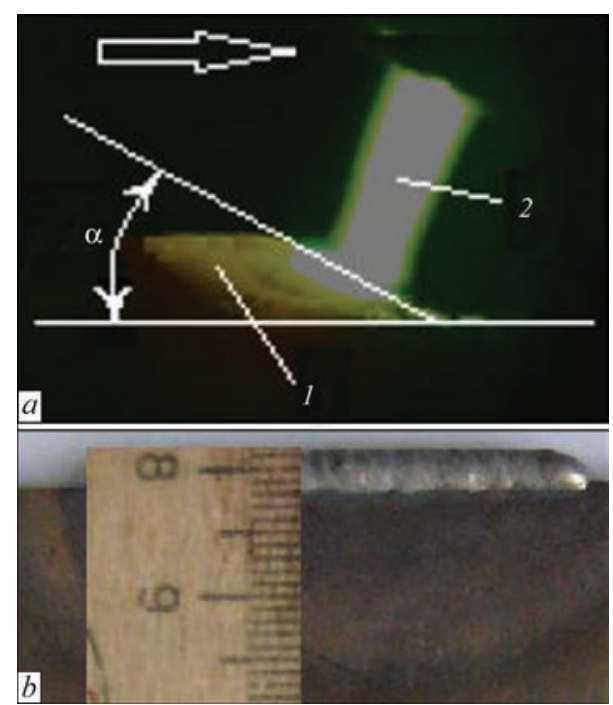

Figure 2. Peculiarities of bead formation in deposition on narrow substrate of 1-2 mm wigth: $a$ - wetting angel $\alpha$ of base and deposited metal on deposit leading edge; $b$ - view of deposited bead; 1 - deposited bead; 2 - microplasma arc (arrow shows surfacing direction) and feed of single microportions of JS32 powder, then further a disperse filler was introduced in a stationary welding micropool by series of $2-5$ microportions. A base metal penetration depth in all the experiments did not exceed $1.5 \mathrm{~mm}$, and fraction of base metal in deposited one made up to $20 \%$. An example of bead deposited on narrow substrate is shown in Figure 2, $b$.

Procedure [7] was used for processing the experimental data and calculation of power indices of surfacing modes. Heat input (taking into account effective efficiency of part heating [1]) was determined as a relationship of microplasma arc heat $Q_{\Sigma}$ entered in anode to given length $L$ of elliptic cylinder of deposited bead. Its cross-section area $F_{\mathrm{b}}$ was calculated on procedure [8].

Analysis of experimental data. The results of experiments (Figure 3 ) indicate that the weld micropool of cross-section to $35 \mathrm{~mm}^{2}$ (approximate volume to $125 \mathrm{~mm}^{2}$ ) is kept on a narrow substrate of $1-2 \mathrm{~mm}$ width under conditions of free formation of the deposited bead. This corresponds to effective height of deposited metal ${ }^{*} h=3-4 \mathrm{~mm}$. A dependence $F_{\mathrm{p}}=f\left(q_{\mathrm{s}}\right)$ in $75-250 \mathrm{~W}$ and $1.5-35 \mathrm{~mm}^{2}$ range is respectively described by a power function of $F_{\mathrm{p}}=a q_{\mathrm{s}}^{n}$ type, the coefficients of which change with narrow substrate width change. Its rise provokes for reduction of inclination of given dependence to abscissa axis, i.e. building up of the cross-section of deposited bead in rise of $q_{\mathrm{s}}>175 \mathrm{~W}$ value takes place more intensively,

${ }^{*}$ Height of rectangle of width $\delta$ inscribed in contour of deposited bead cross-section and from below limited by primary level of nonfused surface of narrow substrate [8]. 
Table 1. Characteristics of modes of MPPS on narrow substrate of 1-2 mm width corresponding to heat input $\mathrm{Q}_{\Sigma} / L$ minimum

\begin{tabular}{|c|c|c|c|c|c|}
\hline$\delta, \mathrm{mm}$ & $q_{\mathrm{s}}, \mathrm{W}$ & $F_{\mathrm{b}}, \mathrm{mm}^{2}$ & $\begin{array}{c}\mathrm{Q}_{\Sigma} / L, \\
\mathrm{~J} / \mathrm{mm}\end{array}$ & $v_{\mathrm{d}}, \mathrm{m} / \mathrm{h}$ & $G_{\mathrm{d}}, \mathrm{g} / \mathrm{min}$ \\
\hline 1.0 & 145 & 6.5 & 490 & 1.15 & 0.9 \\
\hline 1.6 & 170 & 5.5 & 700 & 0.90 & 0.75 \\
\hline 2.0 & 195 & 7.5 & 600 & 1.15 & 0.9 \\
\hline
\end{tabular}

including due to increase of a coefficient of application of disperse filler at expansion of weld micropool [10].

It is determined that a series of modes of MPPS differs by the minimum heat input $490-700 \mathrm{~J} / \mathrm{mm}$ (Figure 4; Table 1) under conditions of discrete-additive formation of the bead on narrow substrate. Such modes are characterized by:

- value of effective arc heat power, which is 25 $40 \mathrm{~W}$ more than its corresponding value sufficient for the beginning of stable formation of the metal being deposited;

- 5.5-7.5 $\mathrm{mm}^{2}$ bead cross-section area and effective height of the deposited metal to $2.0-2.5 \mathrm{~mm}$.

Thus, it is shown that position of the minimum of heat input corresponds to welding current and being 2.5-3.5 A more than its value, at which fusion of narrow substrate base metal takes place.

Increase of heat input in 2-2.5 times at 30-40 W reduction of the effective heat power of microplasma arc from a value of heat energy minimum is caused by a rise of arcing time between feeding the powder microportion for providing corresponding contact angle between base and deposited metal on the deposit leading edge and stable bead formation. 2.5-3 times increase of heat input on the right from the value of minimum heat input was promoted by the necessity of increase of arcing time at entering a series from 2-5 microportions of filler powder into a stable mirror of the micropool.

Sequential increase of effective heat power of the microplasma arc and surfacing efficiency promotes for changes of its rate in $0.4-1.2 \mathrm{~m} / \mathrm{h}$ range (Figure 5). Its maximum values of $0.95-1.25 \mathrm{~m} / \mathrm{h}$ are observed at $F_{\mathrm{b}}=5.5-7.5 \mathrm{~mm}^{2}$. Further, the deposition rate is delayed to $0.4-0.6 \mathrm{~m} / \mathrm{h}$, that is caused by increase of time of micropool filling with the metal being deposited. It is determined that the modes of narrow substrate surfacing, corresponding to the minimum heat input $Q \Sigma / L$ and the maximum deposition rate virtually match (see Figures 3-5 and Table 1), namely $q_{\mathrm{s}} \leq 10 \mathrm{~W}$ $(I \leq 0.63 \mathrm{~A}) ; \Delta v \leq 0.05 \mathrm{~m} / \mathrm{h} ; \Delta \mathrm{Q}_{\Sigma} / L \leq 10 \mathrm{~J} / \mathrm{mm}$.

Deposition efficiency changes in $G_{\mathrm{d} 1} 0.1-2.3 \mathrm{~g} / \mathrm{min}$ range in proportion to $Q_{\Sigma} / L=490-1800 \mathrm{~J} / \mathrm{mm}$ (Figure 6). It makes $0.55-1.20 \mathrm{~g} / \mathrm{min}$ at the minimum values of heat input.

The heat input is in direct proportion to frequency of feed of powder microportions, area of deposited

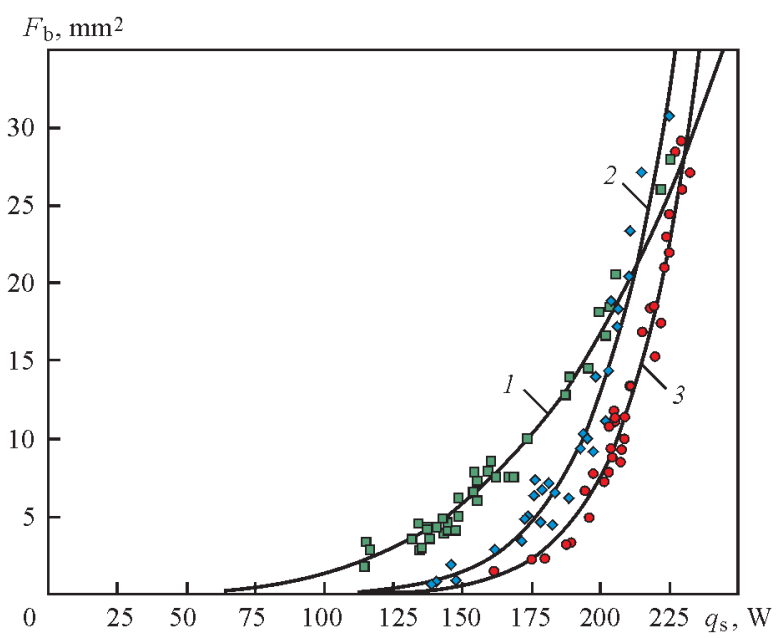

Figure 3. Dependence of cross-section area of deposited bead $F_{\mathrm{b}}$ on effective arc heat power $q_{\mathrm{s}}$ in deposition on narrow substrate (here and in Figures 4-6: 1 - substrate width of 1; 2 - 1.6; $3-2 \mathrm{~mm}$ )

bead cross-section area and deposition efficiency in MPPS on narrow substrate of 1-2 mm width with the minimum penetration depth of base metal. Indicated factors can vary its value in 2.4-3.7 times.

Evaluation of stress-strain state of welded joint in single- and multi-layer surfacing on narrow substrate. Relationship of experimental data (see Figures 4-6) with earlier published results [7, 8] allows assuming that the SSS indices of base-deposited metal welded joint can significantly vary even under conditions of limited effective arc heat power $\left(q_{\mathrm{s}}=\right.$ $=100-250 \mathrm{~W}$ ) and base metal penetration depth (to $1.5 \mathrm{~mm}$ ) in MPPS on narrow substrate of $1-2 \mathrm{~mm}$ width with different levels of $Q_{\Sigma} / L=490-2000 \mathrm{~J} / \mathrm{mm}$.

The corresponding estimation was based on determination of longitudinal compressive strain $\varepsilon_{x y}^{0}$ in a thin plate with $T(z)$ temperature gradient according to calculation scheme of Boley and Weiner [11] in ultimate heating condition and work [12] (approximated evaluation of stresses and deformations of a free band

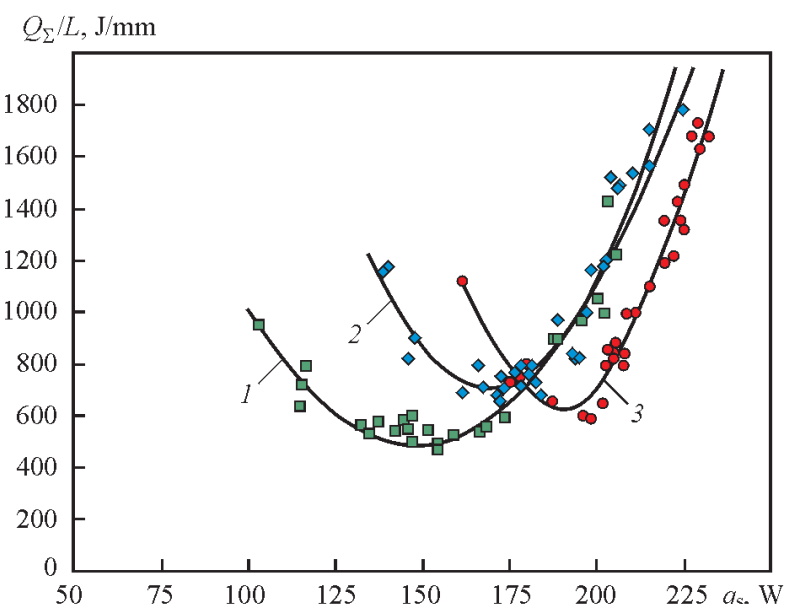

Figure 4. Dependence of heat input $\mathrm{Q}_{\Sigma} / L$ on effective arc heat power $q_{\mathrm{s}}$ in deposition on narrow substrate 


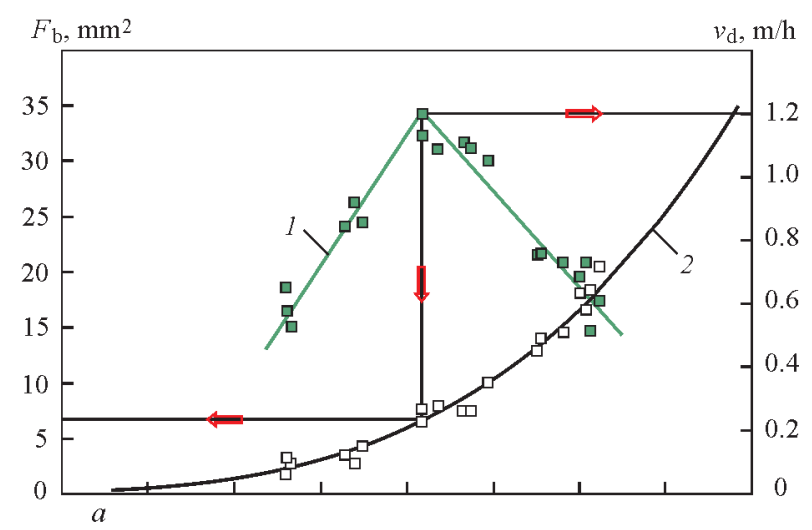

appearing in deposition of bead on one of its longitudinal edges [12-14]).

The following mathematical model was used for calculation of longitudinal deformations in single-axis stressed state appearing in a thin plate with temperature gradient $T$ along axis $z$ :

$$
\begin{gathered}
\varepsilon_{x x}^{0}=\frac{\alpha(T)}{[1-v]} \times \\
\times\left[T(z) d z+\frac{1}{b} \int_{0}^{b} T(z) d z+\frac{12 z}{b^{3}} \int_{0}^{b} T(z) z d z\right] ; \\
\varepsilon_{x x}^{y}=\frac{\sigma_{y}(T)}{E(T)},
\end{gathered}
$$

where $\varepsilon_{x x}^{0}, \varepsilon_{x x}^{y}$ are the complete and elastic longitudinal deformation, respectively; $\alpha(T)$ is the coefficient of linear thermal expansion, $1 /{ }^{\circ} \mathrm{C} ; E(T)$ is the Young's modulus, $\mathrm{MPa} ; v=0.5$ is the Poisson's ratio; $b$ is the size of narrow substrate in the direction of axis $z, \mathrm{~m}$.

The following assumptions and simplifications were taken in the mathematical model described above:

- bead is deposited simultaneously over the whole length of plate edge;

- thermal-deformation processes take place in elastic state, and plastic deformation is determined as a difference of total longitudinal deformations $\varepsilon_{x x}^{0}$ and elastic longitudinal deformations $\varepsilon_{x x}^{y}$ at set temperature value;

- thermal physical dependencies $\alpha(T), E(T)$ and $\sigma_{y}(T)$ for JS32 alloy with crystallographic orientation $<001>$ were taken based on data of works [15, 16] considering their additional extrapolation from $1000-1100^{\circ} \mathrm{C}$ to solidus temperature $T_{\mathrm{S}}$ during nickel heat-resistant alloy solidification;

- in boundary heating state the temperature distribution was set by exponential function of $T(z)=$ $T_{\max } e^{-k z^{2}}$ type, where $T_{\max }=T_{\mathrm{S}}$ condition is fulfilled in point $z=0$.

Such an approach using temperature gradient func-

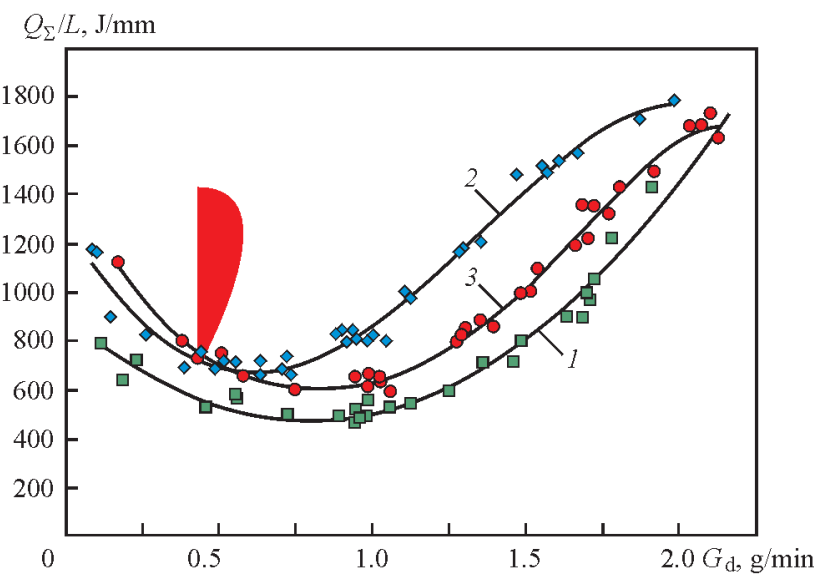

Figure 6. Dependence of heat input $\mathrm{Q}_{\Sigma} / L$ on efficiency of deposition $G_{\mathrm{d}}$ on narrow substrate tion $T(z)$ allowed evaluating the longitudinal deformations $\varepsilon_{x x}^{0}(T)$ for real conditions of single- and three-layer surfacing on narrow substrate of 1-2 mm width, where the base and deposited metal is nickel heat-resistant alloy JS32 <001> with $62-65$ vol.\%. of strengthening $\gamma^{\prime}$-phase. Different modes/conditions of surfacing were modeled by selecting the values of coefficient $k$ based on provisions of isotherm $600{ }^{\circ} \mathrm{C}$ (Figure 7).

Evaluation of the compressive longitudinal deformations in the points of the maximum heating temperatures $T_{\max 1}>T_{\max 2}>T_{\max 3}$ (on current fusion line and its previous positioning levels in the depth of narrow substrate) where indices 2 and 3 are the increasing serial numbers of earlier deposited beads 
relatively to current surfacing) was also carried out taking into account the effective $(0.5 \mathrm{~mm})$ height of the deposited layer for laser and microplasma process $(1.5-5.0 \mathrm{~mm})$ at three-layer surfacing. Figure 8 shows the results of numerical evaluation of gradient of longitudinal deformations $\varepsilon_{x x}^{0}(T)$ along axis $z$ for singleand three-layer surfacing of nickel heat-resistant alloy JS32 under ultimate heating condition.

Evaluation of the SSS in single-layer surfacing of thin plate edge shows that the maximum $\varepsilon_{x x}^{0} \approx 7.5 \%$ and do not depend on value of temperature gradient in HAZ, and amplitude of change of $\left|\Delta \varepsilon_{x x}^{0}\right|$ in the base metal depth under different conditions varies insignificantly from 7.5 to $9.5 \%$. Reduction of the corresponding temperature gradient from 3350 to $70{ }^{\circ} \mathrm{C} / \mathrm{mm}\left(\mathrm{Z}_{600{ }^{\circ} \mathrm{C}}=0.22-10.5 \mathrm{~mm}\right)$ promotes for expansion of HAZ area, subjected to plastic deformation, in more than 20 times.

The plastic defamation zone makes $3-10 \mathrm{~mm}$ for 490-2000 J/mm heat input, corresponding to the conditions of MPPS on 1-2 mm narrow substrate. Evaluation of the SSS in three-layer surfacing of the
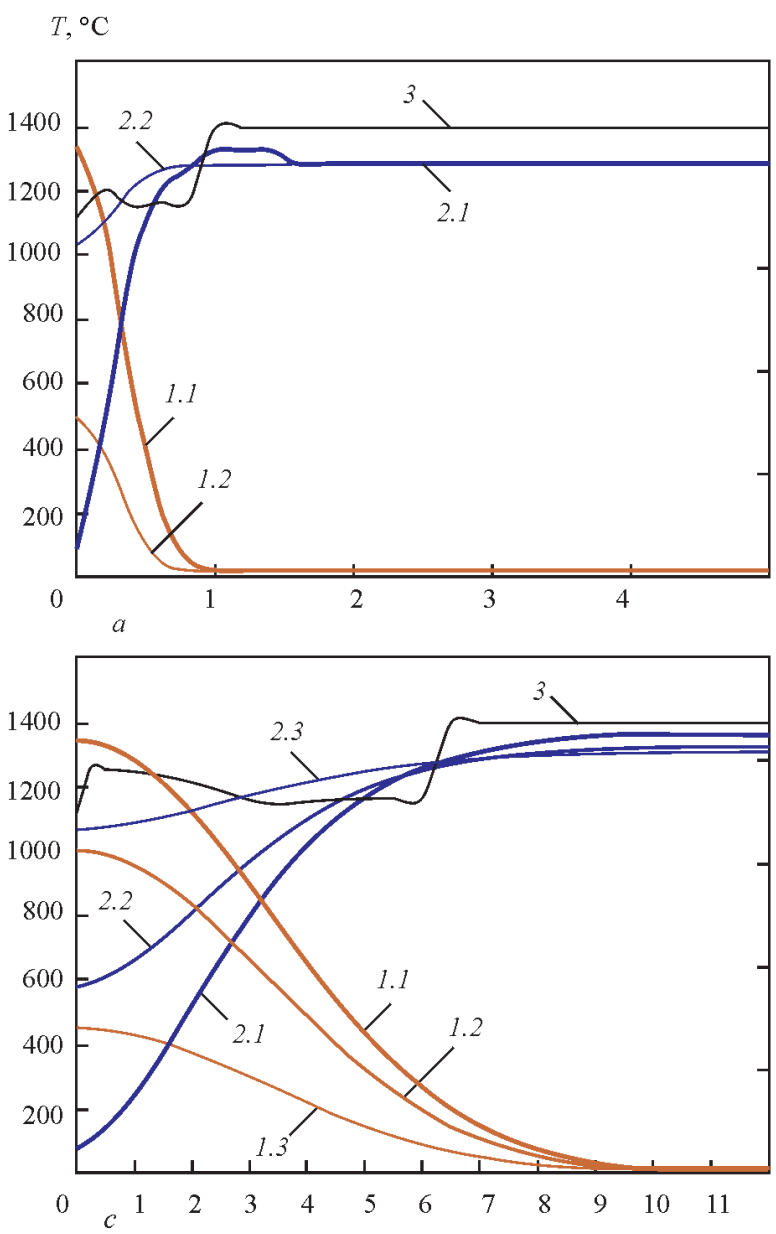

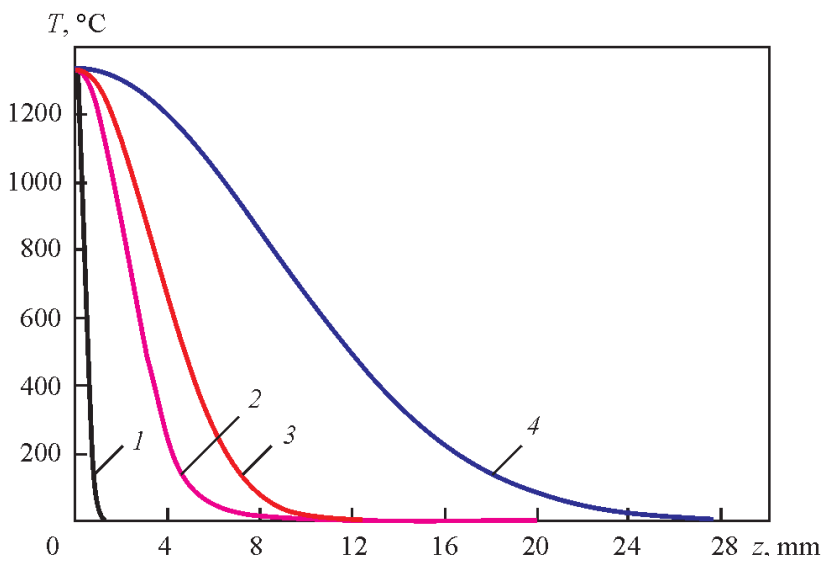

Figure 7. Assumed exponential distributions of $T(z)$ function typical for the following modes of surfacing on $2 \mathrm{~mm}$ narrow substrate: $1-Z_{600{ }^{\circ} \mathrm{C}}=0.22 \mathrm{~mm}$, laser powder surfacing [17-19]; 2, $3-Z_{600{ }^{\circ} \mathrm{C}}=2.2$ and $4.2 \mathrm{~mm}$, MPPS at heat input modes less than $1000 \mathrm{~J} / \mathrm{mm} ; 4-\mathrm{Z}_{600{ }^{\circ} \mathrm{C}}=10.5 \mathrm{~mm}$, MPPS at modes with heat input approximately $2000 \mathrm{~J} / \mathrm{mm}$

thin plate edge shows that increased values of heat input (approximately 1800-2000 J/mm) provides for 40-65\% increase of the total plastic deformations in process of reheating in comparison with its values of less than $1000 \mathrm{~J} / \mathrm{mm}$ (see Figure 8; Table 2). The total
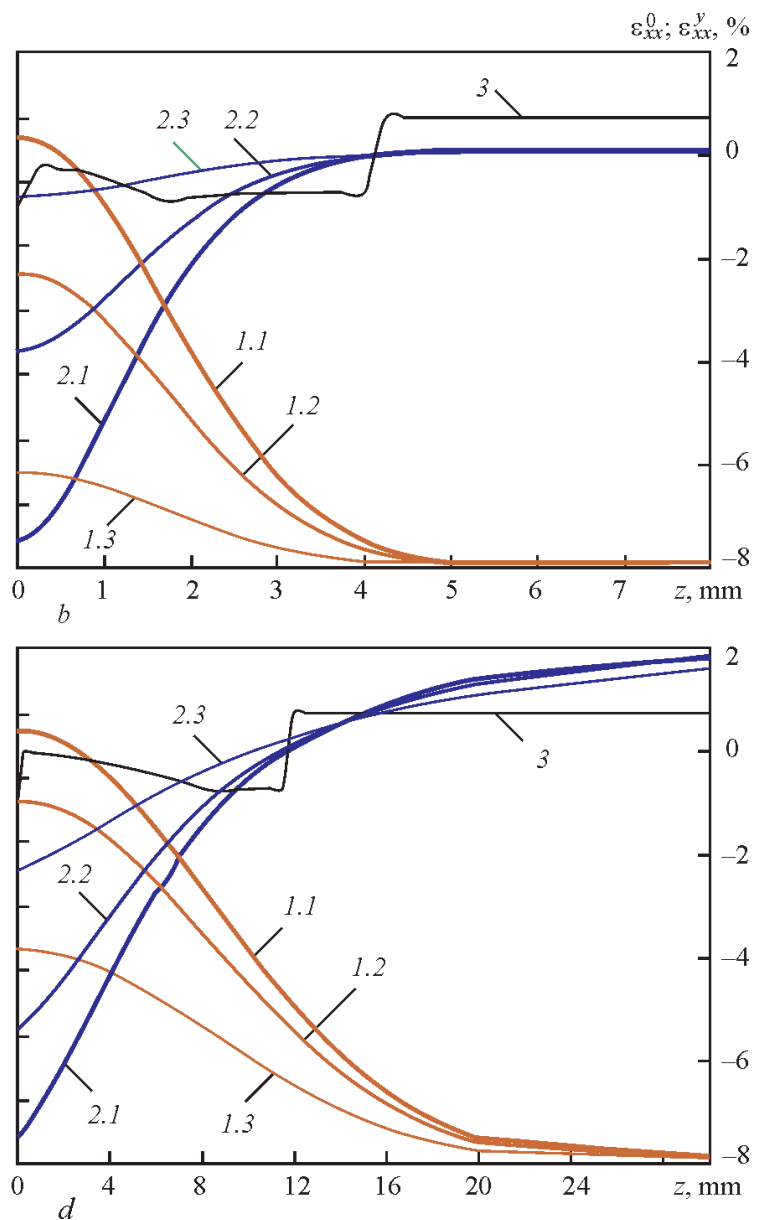

Figure 8. Change of total $\varepsilon^{0}$ distribution in HAZ under conditions of ultimate heating in three-layer surfacing on JS32<001> narrow substrate: 1.1 1.2, $1.3-T(z)$ distribution from fusion line for the last deposited bead and in reheating of two previous ones, respectively; 2.1, 2.2, $2.3-\varepsilon_{x x}^{0}(z)$ distribution from fusion line for the last deposited bead and in reheating of two previous ones, resprctively; $3-\varepsilon_{x x}^{y}(z)$ distribution from fusion line in the last deposited bead at $\mathrm{Z}_{600{ }^{\circ} \mathrm{C}}=0.22(a), 2.2(b), 4.2(c)$ and $10.5(d) \mathrm{mm}$ 
Table 2. Distribution of $\left|\Delta \varepsilon_{x x}^{0}\right|$ at maximum heating and total $\sum$ $\left|\Delta \varepsilon^{0}\right|$ values of amplitudes of longitudinal deformation change depending on temperature gradient $\mathrm{Z}_{600^{\circ} \mathrm{C}}$ in $\mathrm{HAZ}$ for 3-layer deposition on narrow 1-2 mm substrate (acc. to Figure 8)

\begin{tabular}{|c|c|c|c|c|}
\hline \multirow{2}{*}{$\begin{array}{c}\text { Layers } \\
\text { of surfacing }\end{array}$} & \multicolumn{4}{|c|}{$\left|\Delta \varepsilon_{x x}^{0}\right|, \%$, at $\mathrm{Z}_{600^{\circ} \mathrm{C}}, \mathrm{mm}$} \\
\cline { 2 - 5 } & 0.22 & 2.2 & 4.2 & 10.5 \\
\hline First (current) & 7.5 & 7.6 & 8.0 & 9.4 \\
\hline Secons & 1.5 & 3.8 & 4.6 & 7.2 \\
\hline Third & - & 0.8 & 1.5 & 3.9 \\
\hline$\sum\left|\Delta \varepsilon_{x x}^{0}\right|$ & 9.0 & 12.2 & 14.1 & 20.5 \\
\hline
\end{tabular}

values of amplitudes $\sum\left|\Delta \varepsilon^{0}\right|$ change under ultimate heating condition for three-layer surfacing on 1-2 mm narrow substrate at $Q_{\Sigma} / L<1000 \mathrm{~J} / \mathrm{mm}$ does not exceed the maximum values of ductility of alloy JS32 $<001>$ in testing for uniaxial tension $\left(14.5 \%\right.$ at $T \leq 1000{ }^{\circ} \mathrm{C}$, [16]). Together with already obtained practical results $[7,8,20]$ this allows validating the principal possibility for preserving a technological strength in multi-layer MPPS on narrow substrate without a relaxing heat treatment after deposition of each bead.

Evaluation of possible technological effect in full-scale modelling of three-layer MPPS with heat input less than $1 \mathrm{~kJ} / \mathrm{mm}$. A full-scale modelling of technologically probable shape of the bead cross-section, deposited on $2 \mathrm{~mm}$ narrow substrate, per 1 layer with heat input $2000 \mathrm{~J} / \mathrm{mm}$ (Figure 9, $a$ ) and per 3 layers with $600 \mathrm{~J} / \mathrm{mm}$ heat input of layer-by-layer surfacing (Figure 9,b), was carried out in the computer-aided process documentation engineering system Compas-3D V12.

The total heat inputs were taken according to procedure [7] as the criteria of comparative evaluation, and effective height of surfacing $h$ and area of bead side reinforcements $2 \Delta F_{2}$ (see Figure 9) - according to procedure [8]. It is determined that transfer to
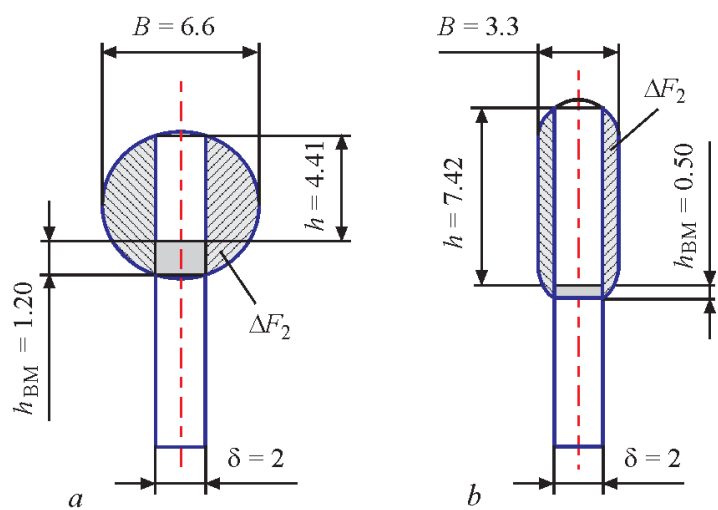

Figure 9. Full-scale modelling of cross-section of beads deposited on $2 \mathrm{~mm}$ narrow substrate with heat input of $2000(a)$ and $600(b) \mathrm{J} / \mathrm{mm}: B$ - deposited bead width; $h_{\mathrm{BM}}$ - depth of base metal penetration; $h$ - effective height of deposited bead; $\Delta F_{2}$ cross-section area of bead side reinforcement which is removed at further machining three-layer surfacing with $Q_{\Sigma} / L=600 \mathrm{~J} / \mathrm{mm}$, together with reduction of the total heat inputs in the part by approximately $10 \%$, allows increasing the effective surfacing height by about $70 \%$ and reducing indirect losses of filler powder (values of machining allowance of deposited bead) roughly in 2 times.

Discussion of investigation results. MPPS with discrete-additive formation can be realized in a range of process parameters, lower boundary of which is limited by the effective power of microplasma arc sufficient for base metal fusion, and upper one - by the limiting volume of weld pool, which can be hold on vertically fixed narrow substrate. Such formation in single-layer surfacing on 1-2 $\mathrm{mm}$ narrow substrate using $\mathrm{Ar}+5 \% \mathrm{H}_{2}$ shielding gas is characterized by the following indices: effective heat power of microplasma arc $q_{\mathrm{s}}=100-250 \mathrm{~W}$; heat input $Q_{\Sigma} / L=$ $=490-2000 \mathrm{~J} / \mathrm{mm}$; average $v_{\mathrm{d}}=0.4-1.25 \mathrm{~m} / \mathrm{h}$; bead cross-section of $1.5-35 \mathrm{~mm}^{2}$ (weld pool volume approximately from 3 to $125 \mathrm{~mm}^{3}$ ); deposition efficiency of $0.1-2.3 \mathrm{~g} / \mathrm{min}$.

Series of modes inside the set range is differ by the lowest heat input 490-700 J/mm, which respectively provides for the lowest total heat input in the part, and being determined by the following combination of indices, i.e. time of existence of metal of weld micropool in molten state of not more than 3-6 s; cross-section area of deposited bead 5-8 $\mathrm{mm}^{2}$; volume of weld micropool approximately $15-25 \mathrm{~mm}^{3}$; fraction of base metal in deposited metal 0.2 ; height of deposited bead $1.5-2.5 \mathrm{~mm}$; deposition efficiency $0.55-1.0 \mathrm{~g} / \mathrm{min}$; average $v_{\mathrm{d}}=0.9-1.25 \mathrm{~m} / \mathrm{h}$.

It was preliminary determined that the considered base-deposited metal welded joints of JS26-JS32 and JS32-JS32 systems at increase of the average total heat input to $5 \mathrm{~kJ} / \mathrm{mm}$ demonstrate cracks, which are sufficiently easily determined by penetrant test-

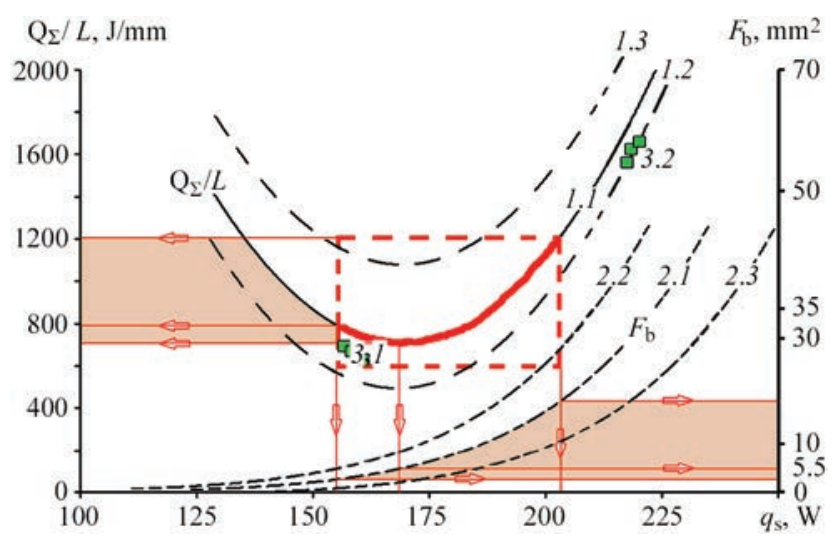

Figure 10. Basic principles for selection of MPPS rational modes depending on $Q_{\Sigma} / L, F_{\mathrm{b}}$ and effective $q_{\mathrm{s}}: 1.1,2.1$ - dependences of $Q_{\Sigma} / L$ and $F_{\mathrm{b}}$ for basic variant of modes $\left(\mathrm{Ar}+5 \% \mathrm{H}_{2}\right) ; 3.1$, 3.2 - rationally and irrational selected pulsed modes; 1.2, 2.2 proposed change due to optimizing the composition of shielding gas/ shielding conditions of weld micropool/quality of disperse filler; 1.3, 2.3 - modes which differ by irrational selection of process parameters, filler powder quality indices or structure of microplasmatron nozzle assembly 
ing. Limitation of heat input of layer-by-layer surfacing at certain maximum allowable values of the total heat input in the part, at which no tendency to crack formation can be observed in the considered welded joints, allows significantly increasing number of layers of the deposited metal and, respectively, height of repaired section on the edge of part of aircraft GTE.

From point of view weldability of nickel heat-resistant alloys, the modes of multilayer surfacing (in prospect 3D surfacing) with the lowest heat input are also the most preferable due to 2.0-3.3 times reduction of width of zone of plastic deformations in HAZ and decrease total plastic deformations in process of reheating by $40-65 \%$, in comparison with the mode at $Q_{\Sigma} / L=1800-2000 \mathrm{~J} / \mathrm{mm}$.

Figure 10 proposes the generalized algorithm for selection of rational modes of layer-by-layer MPPS based on keeping the principle of heat input minimum (by example for the $1.6 \mathrm{~mm}$ narrow substrate). A dashed lines show the range of surfacing modes, which performance of further optimization of its parameters is reasonable by means of application of pulsed surfacing modes, improvement of the conditions for shielding of weld micropool and increase of filler wire quality. The lower values of effective arc heat power, heat input and width of deposited bead, in comparison with corresponding values of indicated indices for direct welding current, are the additional criteria for reasonable choice of process parameters of corresponding surfacing modes with pulsed welding current.

\section{Conclusions}

1. Range of the MPPS process parameters on narrow substrate of 1-2 mm width was evaluated in discrete-additive formation of deposited metal at welding current $5-15 \mathrm{~A}$. It is determined that the series of its modes in $\mathrm{Ar}+5 \% \mathrm{H}_{2}$ shielding gas differs by the lowest heat input $490-700 \mathrm{~J} / \mathrm{mm}$ and is characterized by limitation of bead cross-section and time of existence of weld pool metal in molten state in the $5-8 \mathrm{~mm}^{2}$ and 3-6 s range, respectively.

2. It is shown that such modes of multilayer surfacing of nickel heat-resistant alloys with high content of strengthening $\gamma^{\prime}$-phase differ by 2-3.3 times reduction of the width of plastic deformation zone in HAZ and $40-65 \%$ decrease of the total plastic deformations in the process of reheating. The expected technological effect at approximately similar total heat input is also 2 times reduction of machining allowance value and $70 \%$ increase of effective height of the deposited metal.

3. The new technological principles were proposed for selection of the modes of multi-layer or 3D MPPS of the parts from nickel heat-resistant alloys. They lie in providing the lowest possible level of heat input of such a process, first of all, due to regulation of deposited bead cross-section and time of existence of weld micropool metal in molten state.

1. Frolov, V.V., Vinokurov, V.A., Volchenko, V.N. et al. (1970) Theoretical principles of welding. Moscow: Vysshaya Shkola.

2. Karasev, M.V., Grebenchuk,V.G., Rabotinsky, D.N. et al. (2009) Investigation of influence of semiautomatic gas mixture shielded welding conditions using rectifiers of VD506DK type with flux-cored wire Power Bridge 60M on mechanical and viscous-plastic properties of deposited metal in welding of bridge structures. Svarka i Diagnostika, 4, 19-25.

3. Shipilov, A.V., Konovalov, A.V., Brovko, V.V. et al. (2011) Control of welded joint structure in orbital TIG welding of industrial pipelines of compressor stations. Izvestiya VUZav,. Series Mashinostroenie, 6, 44-52.

4. Paton, B.E., Gvozdetsky, V.S., Dudko, D.A. et al. (1979) Microplasma welding. Kiev: Naukova Dumka.

5. Yarovytsyn, O.V. (2009) Microplasma powder surfacing of refractory nickel alloys containing 45-65\% of $\gamma^{\prime}$-phase: Syn. of Thesis for Cand. of Techn. Sci. Degree. Kiev: PWI.

6. Gladky, P.V., Pereplyotchikov, E.F., Ryabtsev, I.A. (2007) Plasma surfacing. Kiev: Ekotekhnologiya.

7. Yarovitsyn, A.V. (2015) Energy approach in analysis of microplasma powder surfacing modes. The Paton Welding J., $5 / 6,14-21$.

8. Yushchenko, K.A., Yarovitsyn, A.V., Khrushchov, G.D. et al. (2015) Analysis of process of bead shaping in cladding on narrow substrate. Ibid., 9, 20-27.

9. Melekhov, R.K., Pokhmursky, V.I. (2003) Structural materials of power equipment. Properties. Degradation. Kiev: Naukova Dumka.

10. Yushchenko, K.A., Yarovitsyn, A.V., Yakovchuk, D.B. et al. (2013) Some techniques for reducing filler powder losses in microplasma cladding. The Paton Welding J., 9, 30-36.

11. Boley, B., Weiner, J. (1964) Theory of thermal stresses. Moscow: Mir.

12. Okerblom, N.O. (1948) Welding strains and stresses. Moscow; Leningrad: MAShGIZ.

13. Talypov, G.B. (1973) Welding strains and stresses. Leningrad: Mashinostroenie.

14. Nedoseka, A.Ya. (1998) Principles of calculation and diagnostics of welded structures. Kiev: Indprom.

15. Budinovsky, S.A., Kablov, E.N., Muboyadzhan, S.S. (2011) Application of analytical model for determination of elastic stresses of multilayer system in solving of problems on development of high-temperature heat-resistant coatings of aircraft turbine blades. Vestnik MGTU im. N.E. Baumana, Series Mashinostroenie, 26-37.

16. Golubovsky, E.R., Svetlov, I.L., Khvatsky, K.K. (2005) Principles of change of axial and azimuthal anisotropy of strength properties of heat-resistant nickel single crystals for GTE blades. Aviats.-Kosmich. Tekhnika i Tekhnologiya, 26(10), $50-54$.

17. (2001) Melt pool size control in thin-walled and bulky parts via process maps. In: Proc. of $12^{\text {th }}$ Solid Freeform Fabrication Symp. (Austin: Univ. of Texas), 432-440.

18. Vasinonta, A., Beuth, J.L., Griffith, M. (2007) Process maps for predicting residual stress and melt pool size in the laser-based fabrication of thin-walled structures. J. Manufact. Sci. and Eng., 129(1), 101-109.

19. Aggaransi, P., Beuth, J.L. (2007) Localized preheating approaches for reducing residual stress in additive manufacturing. Ibid., 709-720.

20. Zhemanyuk, P.D., Petrik, I.A., Chigilejchik, S.L. (2015) Experience of introduction of the technology of reconditioning microplasma powder surfacing at repair of high-pressure turbine blades in batch production. The Paton Welding J., 8, 39-42. 